\title{
Parents' experiences 12 years after newborn screening for genetic susceptibility to type 1 diabetes and their attitudes to whole-genome sequencing in newborns
}

\author{
Nicola Kerruish, BMBS, PhD ${ }^{1}$
}

\begin{abstract}
Purpose: The potential for utilizing whole-genome sequencing in newborn screening (NBS) has been recognized, but the ethical, legal, and social issues of this may require further analysis. This article begins to address the gap in the literature concerning psychosocial effects of "genomic NBS," focusing on later effects of screening for genetic susceptibility to a single, complex disorder: type 1 diabetes (T1D). It also examines parental attitudes toward potential future expansions of NBS.
\end{abstract}

Methods: Fifteen semistructured interviews were conducted with parents of children who had been tested for genetic susceptibility to T1D 12 years previously.

Results: Parents in this study were not psychologically burdened by knowledge of their child's genetic risk but perceived little benefit.

\section{INTRODUCTION}

The unquestionable success of newborn screening (NBS) coupled with advances in next-generation sequencing has resulted in considerable enthusiasm for combining the two. ${ }^{1,2}$ It has been suggested that "genomic screening" could identify every genetic alteration within a few days of birth to provide ongoing insight into clinical prevention and treatment options for many disease states. ${ }^{3}$

However, incorporating next-generation sequencing into NBS is likely to raise a variety of ethical, legal, and social issues for NBS programs that will be determined, at least in part, by the type of information elicited by testing. This article focuses on the potential for NBS to incorporate tests that predict a range of complex health states. ${ }^{4}$ Also known as susceptibility testing, this type of screening has been loosely defined as "testing for variants that somewhat increase risk for a disease but where many people who test positive will not actually develop the condition."4,5 Such testing has perhaps generated the greatest degree of interest and speculation in the NBS context ${ }^{6}$ and for some specific disorders, such as type 1 diabetes (T1D), research programs are underway. Those involved in such research contend that population-wide genetic screening for T1D risk may ultimately be a practical goal. ${ }^{7}$

However, susceptibility testing differs significantly from more traditional NBS tests: whereas a positive NBS test for conditions
Most of these parents disclosed the result to their child at age 12 years without obvious adverse impact. Parents were unenthusiastic about potential future expansions of NBS to include similar genomic tests.

Conclusions: Absence of adverse psychosocial effects and ease of disclosure to the child represent initial positive findings, but they require replication and further evaluation in relation to uptake of prevention strategies. Attitudes of parents to "genomic NBS" are variable, suggesting that parental choice will be an important component of future screening programs.

Genet Med advance online publication 11 June 2015

Key Words: genetic testing; newborn screening; qualitative; type 1 diabetes

such as phenylketonuria means that the biochemical disorder is already present and the disease will develop rapidly without treatment, a positive susceptibility test gives an individual information about personal risk of development of disease at some point in the future. ${ }^{8}$ The psychosocial impact of such testing in childhood is poorly understood. Whether it is attempts to apply NBS criteria or to assess the validity and utility of susceptibility tests, the arguments of both proponents and skeptics ultimately remain speculative because of a lack of data, including that concerning psychosocial responses of parents and children.

The most significant reason for this evidence gap is that genetic susceptibility testing rarely occurs in childhood. Current data concerning the effects of genetic testing in childhood largely pertain to Mendelian disorders, although even this information is acknowledged to be sparse. ${ }^{9}$ The small body of existing literature suggests that testing in childhood does not adversely affect children's psychosocial well-being. ${ }^{9}$ However, such results cannot necessarily be extrapolated to different types of genetic tests, such as susceptibility tests. There is also a recognized need to move away from assessment of psychopathology and toward more sensitive and appropriate psychosocial assessments, which also acknowledges the social context (particularly the family environment) in which testing occurs. ${ }^{9}$

A few studies have begun to document parental reactions to newborn testing for complex disorders such as T1D in the

'Department of Women's and Children’s Health and Bioethics Centre, University of Otago, Dunedin, New Zealand. Correspondence: Nicola Kerruish (nikki.kerruish@otago.ac.nz) 
context of longitudinal natural history studies. ${ }^{10,11}$ However, even these reports are limited to effects in infancy and, given recent calls to incorporate a more longitudinal approach, ${ }^{9}$ the study reported here aims to provide exploratory data concerning later effects through qualitative interviews with parents 12 years after newborn testing for T1D.

Specific study objectives included:

1. To describe the ongoing impact (if any) on parents of knowledge of their child's genetic risk of T1D

2. To determine details of parental disclosure of genetic risk information to the child

3. To describe parents' perceptions of their child's reactions to this knowledge

4. To describe parents' views about genomic testing more generally

\section{MATERIALS AND METHODS}

\section{The Key Environmental Aspects of Type 1 Diabetes study}

Participants for the study reported here were identified from the pool of families who received an increased risk result in the Dunedin (New Zealand)-based Key Environmental Aspects of Type 1 Diabetes (KEA) study investigating the natural history of T1D (41 infants, $8.2 \%$ of those screened, were found to be at increased risk on the basis of T1D susceptibility genes at $H L A-D R B$ and 38 of these continued into phase II of the KEA study). Increased risk results were disseminated by letter to parents stating that their child was at "increased risk of developing diabetes... with a one in 16 risk...compared to the general population risk of one in 300." A full description of the KEA study protocol has been published elsewhere. ${ }^{11}$ The KEA study itself was discontinued after 3 years due to lack of ongoing funding: at this stage all families of children with increased genetic risk were offered annual antibody surveillance (the appearance of diabetes-related autoantibodies in genetically susceptible young children is highly predictive of future development of T1D). ${ }^{12}$ One child in the cohort developed single-antibody positivity and has been entered into TrialNet. ${ }^{13}$ No children in the cohort have developed T1D.

\section{Psychosocial effects arm of the KEA study}

This cohort of children at increased risk for T1D have previously participated in the psychosocial effects arm of the KEA study involving quantitative assessment of maternal mental state up to 1 year after testing and qualitative interviews with mothers when the child was 3 years of age. ${ }^{11,14}$

The study described here forms part of a comprehensive continuation of this arm that aims to investigate later psychosocial effects. This article describes data from a single interview conducted with mothers of children at increased genetic risk for T1D 12-13 years after newborn testing. The full study involves quantitative psychological analysis of parents and children and focus groups with the children now aged 12-13 years. These will be reported in forthcoming papers.

\section{Participants}

Recruitment. Thirty-five out of 38 (92\%) of the original families who comprised the increased risk group of the KEA study could be contacted and agreed to participate in follow-up. Those who had moved outside the greater Dunedin area were not invited to participate in interviews. Of the remaining 29 families, parents were contacted sequentially, starting with those who had been first to receive the genetic test results as part of the KEA study. Recruitment was discontinued after 15 interviews when a level of "saturation" occurred (when emergence of new themes in the interviews became rare).

Sample characteristics. Fifteen interviews were conducted, all with mothers. Both parents were invited but no fathers wished to participate in interviews. Demographic characteristics of participants are recorded in Table 1. The study was approved by the Central Health and Disability Ethics Committee (ref 13/ CEN/195)

\section{Data collection and analysis}

Interviews were in person, lasted between 30 and 40 minutes, and were conducted by N.K. (author) and J.C. (research nurse). Seven interviews were conducted in participant homes, with the remaining eight occurring in university rooms, according to participant preference. Using semistructured interview guides, participants were asked a series of questions with probes to elicit detailed descriptions of their experiences of and reflections on newborn testing for T1D risk. Questions covered the following: parental understanding of the meaning of the test result; disclosure of the test result to the child; impact of the result on parents, child, and family; parental assessment of harms and benefits; and parental views of the potential for this type of test to be used at a population level, for example, in NBS programs. These question areas were developed in response to preexisting research ${ }^{9,11,14}$ and recommendations that have been made concerning the need for further empirical analysis. ${ }^{9}$

Interviews were audiotaped, transcribed verbatim, and analyzed using thematic analysis. Each transcript was initially coded into broad categories based on the predetermined structure of the interviews, and then more finely by identifying elements of interest across the data. During the process of thematic analysis the transcripts were examined in detail and compared to find repeated patterns of meaning. New themes were generated as connections were made between different aspects of the data both within and between transcripts. The final collection of themes and subthemes (Tables 2 and 3) was developed and refined through this iterative process. ${ }^{15,16}$ This process was conducted by N.K. in conjunction with J.C. for the first five transcripts; N.K. performed subsequent coding and analysis.

\section{RESULTS}

The data have been organized into two broad categories: (i) data related to the parents experiences and views concerning their own child's genetic test and (ii) their views of "genomic screening" more generally. The different themes that occurred 
Table 1 Participant demographics

\begin{tabular}{|c|c|c|c|c|c|c|c|}
\hline $\begin{array}{l}\text { Interview } \\
\text { number }\end{array}$ & $\begin{array}{l}\text { Child } \\
\text { gender }\end{array}$ & $\begin{array}{c}\text { Child age at } \\
\text { interview } \\
\text { (years, months) }\end{array}$ & $\begin{array}{l}\text { Relatives } \\
\text { with T1D }\end{array}$ & $\begin{array}{l}\text { Mother's age } \\
\text { at interview } \\
\text { (years) }\end{array}$ & $\begin{array}{l}\text { Father's age at } \\
\text { time of interview } \\
\text { (years) }\end{array}$ & $\begin{array}{c}\text { Marital } \\
\text { status }\end{array}$ & $\begin{array}{l}\text { Interview when } \\
\text { child was } 3 \\
\text { years old }\end{array}$ \\
\hline 1 & M & 13 years 5 months & N & 46 & 46 & $S$ & N \\
\hline 2 & M & 13 years 2 months & Y (uncle) & 46 & 50 & M & Y \\
\hline 3 & $\mathrm{~F}$ & 12 years 6 months & N & 47 & 47 & M & Y \\
\hline 4 & M & 13 years 4 months & N & 45 & 48 & M & Y \\
\hline 6 & $\mathrm{~F}$ & 13 years 1 month & N & 47 & 53 & M & N \\
\hline 7 & $\mathrm{~F}$ & 12 years 10 months & N & 43 & 48 & M & N \\
\hline 8 & M & 12 years 10 months & N & 48 & 47 & M & N \\
\hline 9 & $\mathrm{~F}$ & 12 years 8 months & Y (second cousin) & 38 & 38 & M & Y \\
\hline 10 & M & 12 years 8 months & $\begin{array}{l}\text { Y (great aunt, } \\
\text { great uncle) }\end{array}$ & 48 & 48 & M & Y \\
\hline 13 & M & 11 years 6 months & N & 39 & 40 & M & Y \\
\hline 14 & M & 11 years 11 months & N & 46 & 45 & M & N \\
\hline 15 & M & 11 years 5 months & $\mathrm{N}$ & 43 & 46 & M & $\mathrm{N}$ \\
\hline
\end{tabular}

T1D, type 1 diabetes; $Y$, yes; $N$, no; $M$, married; S, separated.

in each of these two areas are presented in Table 2 (the meaning and implications of the child's genetic test result) and Table 3 (parental views of genomics more generally) with illustrative statements.

\section{The meaning and implications of the child's genetic test result}

Parental cognitive reactions. Parents in this study generally remembered the "gist" of the information they had been given concerning their child's genetic risk of T1D. For example, some parents still referred to the numbers ( 1 in 16 risk of T1D), whereas others used terms such as susceptible, predisposed, or risk. None of the parents appeared to have unrealistic interpretations of the meaning of the test result. No parents considered their child would definitely develop T1D; conversely, no one believed the risk was zero.

By contrast, parental knowledge of T1D was somewhat variable, generally being restricted to an awareness of the presenting symptoms such as thirst and polyuria. Several parents were unsure whether their child was at risk for type 1 or type 2 diabetes and/or were not sure of the difference between the two conditions. Parents were generally aware that there were shortcomings in their knowledge but had not attempted to gather further information, preferring to wait and see if this became necessary.

Parental emotional reactions. Several parents recalled their initial concern and worry when told of their child's increased risk for T1D soon after birth. However, this had largely abated over the years with parents reassured by their child's good health. Parents generally reported not actually thinking about the test result at all or it being very much at the back of their minds. Interestingly, although parents reported in some ways "identifying" with the condition, for example, by taking particular note when their child told them of a classmate at school with T1D or giving generously to diabetes charities, this did not appear to prompt recurrent episodes of concern about their own child.

Lifestyle and behavioral implications. Despite this lack of concern about their child's test result, it was common for parents to stress that they would consider the diagnosis if their child became unwell with symptoms suggestive of T1D. One parent had thought about diabetes in relation to her child's "excessive" drinking but had managed to monitor the situation and dismiss the diagnosis without consulting a health professional. Other parents also reported being confident in their ability to distinguish between minor illnesses (such as "colds" and "flu") and the onset of diabetes, and reports of consultations with medical professionals prompted by concern around diabetes were very infrequent. One parent whose child had experienced a slightly more protracted period of illness (several weeks of viral-related symptoms) had mentioned the test result to her general practitioner and had been reassured that the doctor had considered and then dismissed the diagnosis.

Most parents felt they had made no changes to their child's or family's lifestyle on the basis of the test result. However, some felt that the test result was an added incentive to aim for as healthy a lifestyle as possible. By this, they generally 
Table 2 The meaning and implications of the child's genetic test result

Theme

Statement

\begin{abstract}
Parental cognitive reactions
Comprehension of results

Recollection of risk To me it just meant that because he had some kind of indicator, genetic indicator, that he was more susceptible perhaps to diabetes (12)

Some knowledge of T1D

It's just at the back of my mind I guess, the symptoms of ... drinking more, getting tired, and things like that (2)

Familiarity/association with T1D

I'm always more aware of a diabetics' collectors, make sure I give more generously to them...to their cause I think, because I identify with that group a bit more (1)

Some early information gathering I remember things like sort of reading Little Treasures [a parenting magazine] articles about it (15)

Minimal recent searching for

information

I've not looked into it. I'll be honest and say there have been times when I've thought about it but never acted on those thoughts (5)
\end{abstract}

Parental emotional reactions

Recall early shock/worry

Worry since abated

..like when he was diagnosed it did send me into a bit of a panic. (12)

Occasional "lingering" concerns

At the time we were a wee bit shocked by it, but now we just carry on and it hasn't been an issue to us or anything (7)

(Occasional "lingering" concerns

A little bit at the beginning... but I probably don't really think about it much anymore. I guess it's just at the back of my mind of...you know the symptoms of drinking more and getting tired and things like that (2)

And I suppose it always, it sits in the back of your mind, I didn't really think about it all that muc (15)

Not actually thinking about the test

We have probably, probably forgotten about it to be honest with you (13)

result

Generally reassured by child's good health

But then he is perfectly fine and I must admit, as he has got older I have got less concerned (8)

Parental/family lifestyle and behavioral implications

Medical "surveillance"

Would think about test result if

child became unwell

Not overattributing illness to T1D

Potential utility

Actively considering T1D when

child became unwell/had

symptoms

Discussing T1D test result with GP when child unwell

Lifestyle modification

Often no change

Possible incentive for generally healthy lifestyle

Focus on diet and exercise

Occasional more specific measures
But I think probably if I had an indicator, if, if there was something about him that made me think "hmm, this isn't what my other children have done," then diabetes would be something that I would probably Google (12)

I haven't been worried about every time she gets sick, it has become fairly obvious that it's just, you know, just a standard flu or... a couple of times she's got a tonsillitis or something and there's always, I've always managed to, you know, eliminate that... (9)

I think... if any other symptoms had come into play then...I would have just gone to my GP and gone straight for this rather than any other testing (10)

He went through a stage where he was wanting to take a drink bottle to bed. I wasn't worried but I thought I will just monitor how long this goes on for and just monitored how much he was probably drinking in the night. Which worked out to be nothing really. He was just taking a drink bottle to bed (10)

He got quite sick and... and a couple of times we did wonder and I think, I did talk to the doctor then actually. And they said no, it's not. But it was just in the back of our minds just to get it checked (4)

I don't think I've really done anything differently with him that I would have done anyway (12)

I honestly don't know if this is a result of the information I was given or something I would have done anyway....but we don't eat anything with any added preservatives...or colors. We make as much of our stuff as what we can (10)

It's more, you know, you should be eating your vegetables (1)

We were giving them kind of a vitamin D...supplement in the winter. And just kind of encouraging them to go outside...I think I read something which suggested that vitamin D was to protect them from those kinds of diseases (15)

Table 2 Continued on next page 
Table 2 Continued

\begin{tabular}{|c|c|}
\hline Theme & Statement \\
\hline \multicolumn{2}{|l|}{ Disclosure to child } \\
\hline \multirow[t]{2}{*}{ Awareness without specific disclosure } & $\begin{array}{l}\text { It's always just been talked about...We've never actually sat down and said....anything about diabetes. Or } \\
\text { you've got an increased risk (1) }\end{array}$ \\
\hline & $\begin{array}{l}\text { I can't even remember when we first told him, I just remember it always being something that we've just kind } \\
\text { of talked about (12) }\end{array}$ \\
\hline $\begin{array}{l}\text { Lack of parental concern about } \\
\text { telling child }\end{array}$ & $\begin{array}{l}\text { To, to my mind it's no difference than knowing that his grandfather had cancer or you know... that he's part } \\
\text { Maori and therefore gets all of those issues as well... there's nothing really to be secretive about (5) }\end{array}$ \\
\hline \multirow[t]{2}{*}{ Superficial information } & $\begin{array}{l}\text { I suppose I just said that he had this blood test when he was born and it showed a very small chance of } \\
\text { developing type } 1 \text { diabetes and we talked about that, what sort of disease that was (15) }\end{array}$ \\
\hline & So, I guess you could say we play it down (12) \\
\hline $\begin{array}{l}\text { Disclosure frequently at age } 12 \text { years, } \\
\text { prompted by this study }\end{array}$ & Probably when you guys rocked up with the new part of the study (3) \\
\hline \multicolumn{2}{|l|}{ Impact on child } \\
\hline \multirow[t]{2}{*}{ Lack of concern or worry } & $\begin{array}{l}\text { I could have told him his hair was going to go curly or something and he would have been the same response } \\
\text { probably (14) }\end{array}$ \\
\hline & $\begin{array}{l}\text { Well, I mean, he is always a bit of a worrier but he doesn't seem to have focused on that particular one. } \\
\text { Doesn't appear to be concerned (15) }\end{array}$ \\
\hline Generally one-off conversation & $\begin{array}{l}\text { He just took it in his stride really. He hasn't asked any more questions. And I think the thing was we just said } \\
\text { look it doesn't mean that it's going to happen. It's just something to watch out for (10) }\end{array}$ \\
\hline Occasional questions, curiosity & $\begin{array}{l}\text { Occasionally, he will ask or bring up the word...but I don't think he worries about it. It would be out of } \\
\text { curiosity but not specifically his result. I think he, he's very blasé about it and maybe that's because I've played } \\
\text { it down (12) }\end{array}$ \\
\hline \multicolumn{2}{|l|}{ Parental assessment of harms and benefits } \\
\hline \multicolumn{2}{|l|}{ Benefits } \\
\hline None & $\begin{array}{l}\text { Not really, that sounds awful. But I guess we have just been part of a study and just to try and help really, but } \\
\text { like I am not at all bothered by it if that makes sense (7) }\end{array}$ \\
\hline Potential & $\begin{array}{l}\text { I don't think there's any benefits for J. I think we learnt a little bit of information... but obviously we haven't } \\
\text { done anything with it so the benefit is that it's there. That, that we may have had a little inkling into what } \\
\text { could have been or what might be. But that would be minute, really (3) }\end{array}$ \\
\hline Benefit of knowledge & $\begin{array}{l}\text { If we didn't do the test we would have been none the wiser. We wouldn't have known about the symptoms } \\
\text { so it was good. We were pleased we done it (4) }\end{array}$ \\
\hline \multicolumn{2}{|l|}{ Harms } \\
\hline $\begin{array}{l}\text { Problems with lifestyle change in } \\
\text { extended family }\end{array}$ & $\begin{array}{l}\text { I think only just with me trying to limit the intake... of treats that he gets. Treats with extended family. That's } \\
\text { been a bit stressful sometimes (1) }\end{array}$ \\
\hline Blood test for antibody surveillance & Oh the heel prick tests were a nightmare. Absolute nightmare with J (5) \\
\hline Effect on siblings & $\begin{array}{l}\text { The only negative impact was my daughter felt under pressure 'cause she went with me when } \mathrm{N} \text { had one of } \\
\text { his blood tests and the person... sort of tried to, not quite coerce her... and she was probably about eight. She } \\
\text { just didn't like needles... But she probably felt a bit negative that she felt like she was almost being forced but } \\
\text { they were trying quite hard to...get her to give blood when she was with her brother. So... she was probably } \\
\text { the one who suffered the negative consequences of it (2) }\end{array}$ \\
\hline
\end{tabular}

Numbers 1-15 inside parenthesis indicate interview numbers.

GP, general practitioner; T1D, type 1 diabetes.

meant following common public health advice such as promoting physical activity and eating a balanced diet including a significant proportion of fruit and vegetables. Occasionally, families used slightly more specific measures such as vitamin $\mathrm{D}$ supplementation because research suggests that vitamin $\mathrm{D}$ could play a role in the prevention and treatment of a number of different conditions, including T1D. Vitamin D deficiency has received some publicity in New Zealand because those who live at the southern-most latitudes may be at risk, particularly during the winter months when sun exposure is minimal. ${ }^{17}$ All of the lifestyle measures that parents mentioned were applied to every member of the household, rather than just the index child.

Disclosure to child. The majority of parents had not discussed the test result with their child until recontacted for this study when the children were approximately 12 years old. Of those who felt that their child had been aware 


\section{ORIGINAL RESEARCH ARTICLE}

\section{Table 3 Parental views of genomics more generally}

Theme

Benefits

Benefit of knowledge for individual and society

Potential for early diagnosis or prevention

Concern that benefits may not accrue as science imperfect and difficult to change behavior

Harms

Potential for worry and overprotective behavior

Personality-specific

Potential for misunderstanding among parents and children

Potential disruption of family dynamics

\section{Timing}

Not during the newborn period

Prefer later in childhood

Delivery of results

Not online

Health professional

Tailored to the individual of things on top it (5)
I mean, you know, knowledge is power. The more you have the better (5)

Because if it's good for the person, it's good for the, it saves the health system money, there's all sorts of benefits for the individual and society (6)

Well, there's definite benefits. I mean it's, anything that's, you know, looked at early if there is that sort of thing going to happen or if it is starting to develop well then there's, there's definite benefits to that (3)

Sometimes those things don't always work either do they? It's like don't do this for cancer but...it doesn't matter how many veggies you eat you can still get cancer (13)

I think it depends whether you think it will change people's behavior...I'm not convinced it will...people do lots of things that are bad for their health and know about them and it makes no difference (6)

But a negative side of it is that it could probably put a lot of worry onto people as well that maybe unnecessary (7)

Depending what it was you could perhaps stop them doing some things that they may have wanted to do if it was going to be potential risk... I guess the potential's there to probably wrap them up in cotton wool a little bit depending what the genetic testing was (10)

Even looking at families the kids have grown up with like how often some mothers might take their children to the doctor just for a wee sniffle. Whereas most of us will ride it out for a couple of days and see how it's going to go...there would be some that you could imagine would be very paranoid about it. I don't know actually, that could open a whole another can of worms with people being paranoid about all sorts of things (6)

I think maybe getting that across to people is quite tricky depending on what their background is (2)

There could be a lot of paranoia... and you could actually probably worry the children, unnecessarily depending on how it's explained... Everyone's different in how they explain things to their kids. We don't tend to worry them. we've been open with them with everything...it's a matter of being able to tell them but also reassuring them that this might never happen (6)

Would it change how you felt about your child? If you had a family group of children and you know that's the black sheep. That's the one that's got that thing. Are you going to treat them differently? How's that going to affect the family? There are so many unknowable things as to how you would cope with it, that it would almost be better off not knowing (5)

I mean 'cause when you have a newborn baby how you do parenting in itself is hard let alone a whole extra layer

You think you are fine at the time but in hindsight you have got this little bundle of joy that you just think, is the most marvelous thing... and then to find out is very hard. Maybe later, maybe when the nappy [diaper] brain thing, has moved on. You do have a lot going on with a newborn (8)

I don't think off the net. Because then that sort of cheapens the results for want of a better word. I think that it's nice for the results to be personal (1)

It's not like something that should be delivered in the mail really is it? That's the kind of thing you need to have a discussion with someone who knows about it, really. It's not like internet shopping (11)

I like a personal approach. I think if you want people to act on the results and improve their health then there's got to be that follow-up from the GP or a nurse or something (1)

Maybe just have somebody available or some information available when you needed it. Not when you don't, you know sometimes people come to you and fill you full of information, but you're not ready to, to hear it so maybe it needs to be when you're ready for it. Not when somebody else thinks they need to come and tell you about it (8) 
Table 3 Continued

Theme

Statement

Features of conditions tested for

Preventability

If there was an intervention or something you could do, then I think it's really beneficial (6)

Seriousness

It would have to be something quite serious. Something like that then I can understand why people would definitely want to get tested. But the things that you can live with, I don't think it's necessary (8)

Prevalence If there was particular things which were sort of really prevalent I suppose things like asthma, I mean it would be helpful to know in advance (15)

I mean if it was something that you knew one in three people who have this are going to get that really bad horrible thing. Well, then maybe that percentage is worth knowing. But if you're talking about one in a thousand. Do you need to know? Is, is that stress that it's going to put on your family worth it? (5)

So your chances might be quite small but you could die overnight of it. It might be worth knowing (3)

Multiplex testing

I wouldn't like to be given a long "checklist" of conditions for a beautiful healthy baby (9)

Concern about where and how to draw the line

Where do you draw the line as to what you can and can't test for... probably the most common diseases. I don't know actually. Where do you draw the line again? I suppose things that are, like your obesity and things like that, that are the most prevalent... but then again you know cost comes into a factor too, doesn't it? And where do you draw the line? (6)

Numbers 1-15 inside parenthesis indicate interview numbers.

GP, general practitioner

of the information prior to this, most could not remember a specific discussion and felt that the information had "just always been talked about." In all cases it was the mother who talked to the child about the test result and its meaning. None of these mothers reported being concerned or worried about telling their child about their genetic status. They reported keeping the information fairly superficial, largely because they felt this was appropriate for their child's level of understanding, but also as a way of ensuring the child was not upset. Several parents stated that it would have been difficult for them to explain anything in more detail anyway because they did not feel competent to discuss genetics or T1D at a higher level. Parents whose children knew an individual with T1D usually used that person as an example of the condition and its "manageability," while at the same time stressing that the child had a genetic risk factor rather than the actual disease.

Impact on child. This apparent lack of concern on the part of parents may have been influenced by the fact that they all reported that their children had not been upset or worried about the information. Parents reported that their children viewed the information quite "matter of factly", simply absorbing and assimilating it as they would many other types of knowledge. Generally, the disclosure constituted a brief one-off discussion, but if children did ask questions or revisit the subject, this tended to be fairly low-key.

Parental assessment of harms and benefits. When asked to review the overall benefit of having received this genetic risk data concerning their child, several parents considered there had been no direct benefit. They were generally pleased to have been able to assist with a research study but did not view the actual genetic testing process as beneficial. Other parents commented on the potential for benefit (should their child become unwell), which they sometimes construed as a very minor benefit. However, a few parents did place a little more weight on the benefits of simply knowing regardless of whether this information was ultimately going to impact their child's health and well-being.

In relation to harmful effects, again, many of the parents thought that there had been no adverse effect. Several commented that the regular follow-up blood tests (to assess for the development of autoantibodies) were difficult, although they acknowledged that these had stopped by the time the children were old enough to remember them (because the KEA study had been discontinued).

Other parents felt that while they were trying to implement healthy lifestyle strategies (in part related to risk of T1D, although they had received no specific advice in this regard), this sometimes led to difficulties with extended family members who may want to give treats to the child. Finally, one mother felt that her daughter (whose brother had been tested as part of the KEA study) was uncomfortable when she was put under some pressure to agree to a genetic test herself. Interestingly, none of the parents brought up the potential to worry about their children when asked about the harms they may have experienced as a result of their child being tested for genetic susceptibility to T1D.

\section{Parental views of genomics more generally}

Harms. By contrast, when asked about the potential downside of other people's children being tested (i.e., population screening), many of the parents talked about the potential for worry and overprotective behavior. They frequently commented that this would likely apply more to some people than to others, but that it could be very difficult to predetermine this. Parents frequently discussed the potential difficulties of explaining such genetic 
test results to people, including to the children themselves, and that doing so might disrupt "family functioning." The issue of knowing such test results when applying for insurance was also raised.

Benefits. However, parents did also see a range of advantages from testing, largely related to awareness, early detection, and prevention of disease. These varied in relation to the following.

Features of the conditions: The most frequent comment concerning what type of conditions might be included in such testing was that there should be something that could be done to prevent it or minimize the risk. Several parents, however, noted the scientific limitations with some of these predictions, limited availability of preventative measures, and that many people would end up undertaking preventative measures "unnecessarily." Some were skeptical that a genetic test result would assist in the difficult task of changing people's behavior.

Opinions varied with regard to other test parameters. Some parents felt it was only worth testing for serious conditions (not for conditions "you can live with"), whereas others felt that knowing about a potentially life-limiting condition would be too stressful. Other parents thought that testing should only be considered if the test predicted a high (e.g., 1 in 3) chance of developing the condition, whereas some felt it would be worth including conditions whereby "your chances might be quite small but you could die overnight." Several parents discussed how difficult it would be to know where to draw the line, and also that receiving a long checklist of abnormalities could be very intimidating.

Timing: Many of the parents discussed the timing of such testing, feeling that the newborn period was not the right time and that if testing were to occur at all, later in childhood would be preferable. Reasons for this viewpoint included the intensity of parenting at this early stage, the effects of tiredness and postpartum hormonal changes on maternal mental state, and the potential to alter bonding between parent and child.

Delivery of results: All of the parents were strongly against the use of online services to deliver test results. They generally preferred the idea of the results (and subsequent support) being from a general practitioner, and they stressed the need for that person to be appropriately trained and for their advice to be tailored to the individual family. Parents preferred this type of approach, not only for personal reasons but also because they believed that this would increase the chances that appropriate changes in behavior would be made and that inappropriate and potentially costly pursuits of unproven prevention strategies would decrease.

\section{DISCUSSION}

This study provides preliminary data concerning the longer-term effects of NBS for genetic susceptibility to T1D. The key findings are that 12 years after testing, the parents interviewed had largely relegated their child's genetic risk of T1D to the back of their minds and it appeared to have very little ongoing impact on their family lives. Many of the parents had only disclosed the information to their child when prompted by the study described here, but they reported no difficulty in doing so, or any obvious adverse impact on their child. Although some of the parents considered there to be no or minimal direct benefit of genetic testing for susceptibility to T1D, most viewed the genetic knowledge as potentially useful in directing further investigations should their child become unwell. Concern about harmful effects of testing was minimal. This contrasted with a much more ambivalent attitude to the prospect of future expansions of NBS to include similar genomic tests, with a greater focus on the potential harms.

Data from these interviews did not reveal any significant adverse psychosocial consequences in the participants, although with a sample size of 15 this cannot necessarily be extrapolated to other parents. Despite this limitation, the finding is consistent with an evolving body of literature documenting an absence of quantitative evidence that receiving genetic test results for Mendelian disorders leads to any significant adverse impact on children's psychosocial well-being. ${ }^{9}$

Although the parents in this study did not consider that either they or their children had been adversely affected, several parents mentioned that symptoms of illness could raise concern about the development of T1D. Depending on the degree, one could perceive this as an adverse psychological consequence. At the same time, many of the parents in this study saw little benefit in knowing about their child's genetic risk of T1D and thought very little about it. So, although in some ways it is reassuring to think that families do not feel psychologically burdened by such information, these data might add to concerns regarding whether susceptibility test results will provide sufficient motivation for parents to implement prevention measures if and when these become available. ${ }^{18}$ Emerging empirical literature on the role of genetic risk in health behavior change in adult populations suggests little impact. ${ }^{19}$

The parents interviewed in this study reported finding it relatively straightforward to inform their 12- to 13-year-old children of a genetic risk of T1D. Although we know very little about the optimal time to deliver such information to a young person, it is possible that approximately 12 years of age, when most children are developing formal operational thought processes and their identities are evolving, ${ }^{20}$ represents a good starting point. However, it should also be noted that prior to recontact for this study, most parents had, in fact, not informed their child of the result. While this is understandable given the nature of the testing (part of a research study that had been discontinued) and the absence of any known prevention measure, it could suggest a degree of parental concern about the process. Whatever the reason for non-disclosure, the finding suggests that parents will require ongoing assistance in communicating such information in a productive way, particularly if some type of preventative measure (such as lifestyle modification) is to be recommended. This is also consistent with existing literature concerning disclosure of risk of Mendelian disorders to children, which highlights the need for help and support if parents are to achieve successful communication. ${ }^{21}$

Several recent reports have suggested that parents are likely to be enthusiastic about accessing genomic health information 
concerning their children. ${ }^{22,23}$ By contrast, parents in this study raised a host of concerns and were generally unenthusiastic about the prospect of "genomic NBS." This difference may be related to the testing situation being "less hypothetical" for the parents described here than those in the general population. In this study, parental opinions regarding which test parameters may be important also varied considerably, consistent with previous research suggesting that only one-third of parents are interested in testing their children when there is no available treatment. ${ }^{24}$ This study therefore adds to existing data suggesting that different types of information derived from whole-genome sequencing will appeal more to some parents than to others, and contrasts significantly with parental attitudes to existing NBS programs for which acceptance and uptake rates are very high. ${ }^{25}$ Parents in this study also felt strongly (arguably based on their own experience) that testing (or delivery of results) should not occur during the newborn period. This concern has been raised previously, ${ }^{26}$ but the allure of a well-established population screening program clearly remains strong given the current research agenda.

\section{Limitations}

The study has several limitations. First, the sample size is relatively small, limiting generalizability. Second, the genetic testing reported here was part of a study of the pathogenesis of T1D. Parental motivations for testing may be more related to beliefs about the value of research rather than an interest in genetic risk information itself. Therefore, these parents may differ from a group of parents who had more actively chosen such testing for their child (if it were available). Third, the study reports on genetic testing for a single condition, whereas future possibilities include the possibility of multiplex testing.

\section{Conclusion}

The findings of this exploratory study provide important insights into the experiences of a group of parents 12 years after newborn testing for genetic susceptibility to T1D. The key findings point to some important considerations for research investigating future development of NBS programs. Of particular note, parents in this study with direct experience of NBS for genetic susceptibility to T1D were much less enthusiastic about expanding NBS to incorporate nextgeneration sequencing than parents in the general population have been reported to be. This reinforces the need to investigate mechanisms that enable parents to make choices concerning the timing and types of genomic risk information they want to receive. ${ }^{4}$

Similarly, although it is reassuring that parents in this study did not appear to worry unduly about their child's risk of T1D, the appropriate balance between parental concern and motivation for behavior change/prevention strategy (should they be developed) remain unclear. Unpacking this relationship will be critical to understanding the ultimate utility of susceptibility testing for complex disorders. More specifically, future research needs to more adequately describe the relationship between genetic risk information, parental ratings of their child's health and development, parenting style, and health-related behavior in the context of the family. Such studies should endeavor to include young people themselves, adopt longitudinal approaches, and use sensitive measurement techniques that explore potential positive aspects of genetic knowledge, as well as potential harms. ${ }^{4}$

\section{ACKNOWLEDGMENTS}

This study was funded by a University of Otago Research Grant. The author is grateful to Jane Columb (research nurse) for assistance with interviewing and to Stephen Robertson for helpful comments concerning the first draft of this paper.

\section{DISCLOSURE}

The author declares no conflict of interest.

\section{REFERENCES}

1. Levy HL. Newborn screening: the genomic challenge. Mol Genet Genomic Med $2014 ; 2: 81-84$

2. NIH website. NIH program explores the use of genomic sequencing in newborn healthcare News release2013. http://www.nih.gov/news/health/sep2013/ nhgri-04.htm. Accessed 7 January 2015.

3. Human Genetics Commission and National Screening Committee UK. Profiling the Newborn: A Prospective Gene Technology? 2005. http://217.35.77.12/ archive/england/papers/health/pdfs/Final\%20Draft\%20of\%20Profiling \%20 Newborn\%20Report\%2003\%2005.pdf.

4. Wade $\mathrm{CH}$, Tarini BA, Wilfond BS. Growing up in the genomic era: implications of whole-genome sequencing for children, families, and pediatric practice. Annu Rev Genomics Hum Genet 2013;14:535-555.

5. Roberts JS, Dolinoy DC, Tarini BA. Emerging issues in public health genomics. Annu Rev Genomics Hum Genet 2014;15:461-480.

6. Wilcken B, Wiley V. Fifty years of newborn screening. J Paediatr Child Health 2015;51:103-107.

7. Hagopian WA, Erlich H, Lernmark A, et al.; TEDDY Study Group. The Environmental Determinants of Diabetes in the Young (TEDDY): genetic criteria and international diabetes risk screening of 421000 infants. Pediatr Diabetes 2011;12:733-743.

8. Kerruish NJ, Robertson SP. Newborn screening: new developments, new dilemmas. J Med Ethics 2005;31:393-398.

9. Wade $\mathrm{CH}$, Wilfond $\mathrm{BS}, \mathrm{McBride} \mathrm{CM}$. Effects of genetic risk information on children's psychosocial wellbeing: a systematic review of the literature. Genet Med 2010;12:317-326

10. Bennett Johnson S, Baughcum AE, Carmichael SK, She JX, Schatz DA. Maternal anxiety associated with newborn genetic screening for type 1 diabetes. Diabetes Care 2004;27:392-397.

11. Kerruish NJ, Campbell-Stokes PL, Gray A, Merriman TR, Robertson SP, Taylor BJ. Maternal psychological reaction to newborn genetic screening for type 1 diabetes. Pediatrics 2007;120:e324-e335.

12. Devendra D, Liu E, Eisenbarth GS. Type 1 diabetes: recent developments. BMJ 2004;328:750-754.

13. Type 1 Diabetes TrialNet. http://www.diabetestrialnet.org/. Accessed 3 March 2015.

14. Kerruish NJ. Parents' experiences of newborn screening for genetic susceptibility to type 1 diabetes. J Med Ethics 2011;37:348-353.

15. Rice PL, Ezzy D. Qualitative data analysis. In: Singh R (ed). Qualitative Research Methods: A Health Focus. Oxford University Press: Oxford, UK, 1999:295.

16. Braun V, Clarke V. Using thematic analysis in psychology. Qual Res Psychol 2006:3:77-101.

17. New Zealand Ministry of Health. Vitamin D. http://www.health.govt.nz/yourhealth/healthy-living/food-and-physical-activity/nutrition/vitamin-d. Accessed 3 March 2015

18. Marteau TM, Weinman J. Self-regulation and the behavioural response to DNA risk information: a theoretical analysis and framework for future research. Soc Sci Med 2006;62:1360-1368. 


\section{ORIGINAL RESEARCH ARTICLE}

19. Heshka JT, Palleschi C, Howley H, Wilson B, Wells PS. A systematic review of perceived risks, psychological and behavioral impacts of genetic testing. Genet Med 2008;10:19-32.

20. Fanos JH. Developmental tasks of childhood and adolescence: implications for genetic testing. Am J Med Genet 1997;71:22-28.

21. Metcalfe A, Coad J, Plumridge GM, Gill P, Farndon P. Family communication between children and their parents about inherited genetic conditions: a metasynthesis of the research. Eur J Hum Genet 2008;16:1193-1200.

22. Goldenberg AJ, Dodson DS, Davis MM, Tarini BA. Parents' interest in wholegenome sequencing of newborns. Genet Med 2014;16:78-84.
23. Waisbren SE, Bäck DK, Liu C, et al. Parents are interested in newborn genomic testing during the early postpartum period. 2015;17:501-504.

24. Tarini BA, Singer D, Clark SJ, Davis MM. Parents' interest in predictive genetic testing for their children when a disease has no treatment. Pediatrics 2009;124:e432-e438.

25. Nicholls SG, Southern KW. Parental decision-making and acceptance of newborn bloodspot screening: an exploratory study. PLOS One 2013;8: e79441.

26. Ross LF. Against newborn screening for type 1 diabetes. Arch Pediatr Adolesc Med 2007;161:616-7; author reply 617. 